\title{
Catheter-based Renal Denervation for Therapy of Hypertension: Is There a Hope for Its Resurgence?
}

\author{
${ }^{1}$ Sebastian Ewen, ${ }^{2}$ Lucas Lauder, ${ }^{3}$ Michael Böhm, ${ }^{4}$ Felix Mahfoud
}

\begin{abstract}
Hypertension (HTN) is the most common chronic cardiovascular disease with increasing prevalence all over the world. Despite the availability of many effective antihypertensive drugs, blood pressure control to target values remains low. Resistant hypertension is defined as "blood pressure above goal in adherent patients despite a triple antihypertensive therapy in maximum or maximum tolerated doses, including a diuretic, which is found in approximately 8 to $18 \%$ of all hypertensives'. Treatment requires a multimodal therapy concept, including-polypharmacy, lifestyle modification and a systematic identification of secondary causes of HTN or pseudoresistance. Increased activity of the sympathetic nervous system has been identified as main contributor to the development and maintenance of resistant HTN. Catheterbased renal denervation has been introduced as a minimal invasive option for patients with resistant HTN. However, the clinical evidence in support of renal denervation as an effective interventional technique is conflicting. A number of observational studies and four randomized, controlled trials (Symplicity HTN-2, Prague 15, RSD-LEIPZIG and DENERHTN) support both safety and efficacy of this new therapy, but some smaller studies and the large, single-blind, randomized, sham-controlled Symplicity HTN-3 trial failed to show superiority of renal denervation when compared to medical therapy alone. The present review aims at providing an overview about catheter-based renal denervation for treatment of HTN.
\end{abstract}

Keywords: Hypertension, Renal denervation, Symplicity, Therapy resistance.

How to cite this article: Ewen S, Lauder L, Böhm M, Mahfoud F. Catheter-based Renal Denervation for Therapy of Hypertension: Is There a Hope for Its Resurgence? Hypertens J 2015;1(1):45-50.

Source of support: Nil

Conflict of interest: None

\section{INTRODUCTION}

Hypertension (HTN) is highly prevalent and one of the most frequent chronic diseases worldwide. ${ }^{1}$ Prognoses for the next decades suggest that up to $50 \%$ of the adult population will be diagnosed hypertensive, using the

\footnotetext{
${ }^{1-4}$ Klinik für Innere Medizin III, Kardiologie, Angiologie und Internistische Intensivmedizin, Universitätsklinikum des Saarlandes, Homburg/Saar, Germany
}

Corresponding Author: Sebastian Ewen, Klinik für Innere Medizin III, Kardiologie, Angiologie und Internistische Intensivmedizin, Universitätsklinikum des Saarlandes, Kirrberger Str. Geb. 4066421 Homburg/Saar, Germany, Phone: +49 684116 21346, Fax: +496841 16 13211, e-mail: sebastian.ewen@uks.eu standard guideline definitions of HTN. ${ }^{1}$ Approximately, 8 to $18 \%$ of all patients with high blood pressure (BP) are resistant to drug treatment, defined as-uncontrolled blood pressure (>140/90 mm Hg; >130-139/80-85 mm $\mathrm{Hg}$ in patients with diabetes mellitus; $>130 / 80 \mathrm{~mm} \mathrm{Hg}$ in chronic kidney disease with proteinuria) despite the use of at least three antihypertensive agents of different classes, including a diuretic, at maximum or highest tolerated doses..$^{2-4}$ Attention should be paid to differentiate between true resistance and pseudoresistance, which is probably related to poor medication adherence, situational evoked blood pressure elevation (white-coat hypertension), or suboptimal drug combination. ${ }^{5}$ In approximately $20 \%$ of all patients suffering from resistant HTN, a secondary, potentially reversible cause can be found, which should be excluded systematically in all such individuals. ${ }^{2,5}$ Current noninvasive therapeutic strategies are mainly based on lifestyle interventions and pharmacological treatment. ${ }^{4}$ There is evidence that the sympathetic nervous system contributes to the development and progression of almost all phenotypes of HTN, which is consequently a relevant target for new therapeutic strategies. ${ }^{6,7}$ The present review evaluates the treatment of resistant HTN by catheter-based renal sympathetic denervation (RDN).

\section{ROLE OF THE RENAL SYMPATHETIC NERVOUS SYSTEM}

Increased sympathetic nervous activity contributes to the pathophysiology of numerous cardiovascular diseases, including - HTN, heart failure, chronic kidney disease, metabolic syndrome and frank diabetes. ${ }^{7,8}$ The sympathetic nervous system provides the kidneys with efferent (axons located in the thoracic and lumbar sympathetic trunk), and receives information for the central nervous system via afferent (cell bodies ipsilateral Th6-L4) fibers by mechano- and chemoreceptors. The efferent fibers innervate the renal vasculature, the tubular segment of the nephron and juxtaglomerular renincontaining granular cells. ${ }^{9}$ Key mechanisms of efferent stimulation at the kidneys are-tubular sodium retention via adluminal basolateral $\mathrm{Na} / \mathrm{K}$ adenosine triphosphatase, mediated by $\beta 1$-adrenoceptors; a reduced renal blood flow mediated by $\alpha 1$-adrenoreceptors and renin release of the juxtaglomerular apparatus mediated 
by $\beta 1$-adrenoceptors. ${ }^{9}$ These effects influence short and long-term blood pressure regulation. ${ }^{7}$

\section{CATHETER-BASED RENAL DENERVATION}

A minimally invasive, catheter-based, radiofrequency or ultrasound-based method to directly target renal sympathetic nerves has been introduced into clinical practice. Currently, seven CE-certificated RDN-catheters are available (Medtronic ${ }^{\circledR}$ Symplicity Flex, Spyral, St Jude $^{\circledR}$ EnligHTN, Vessix ${ }^{\circledR}$ The V2, Terumo ${ }^{\circledR}$ Iberis, Cardiosonic ${ }^{\circledR}$ TIVUS, and Recor ${ }^{\circledR}$ Paradise). Alternative, new devices are currently under investigation with catheters that facilitate micro needle delivery of guanethidine or ethanol to target the renal sympathetic nerves (e.g. Mecator MedSystems ${ }^{\circledR}$ Bullfrog infusion catheter, Ablative Solutions ${ }^{\circledR}$ Peregrine catheter).

Via a femoral (or radial) access, a special catheter is inserted percutaneously and advanced to the distal segment of the renal artery under fluoroscopy using a guiding catheter (e.g. renal double curve or internal mammary artery). The vessel wall is focally heated up to a maximum of $70^{\circ} \mathrm{C}$ by means of high-frequency or ultrasound energy, while the vessel is cooled intraluminally by the high renal blood flow. The focal heating destroys the sympathetic nerve fibers located in the adventitia. Renal sympathetic nerves are more abundant in the anterior area of the arterial ostium. ${ }^{10}$ However, recent studies have shown that in the proximal segments of renal artery these nerves are localized $>5 \mathrm{~mm}$ from the lumen (Fig. 1), a distance which may be beyond the ablation depth of at least the currently used radiofrequency based catheters, which approximately achieve a depth of 3 to $4 \mathrm{~mm} \cdot{ }^{11,12}$ Due to the close run of sympathetic nerves and $C$ pain fibers, during ablation

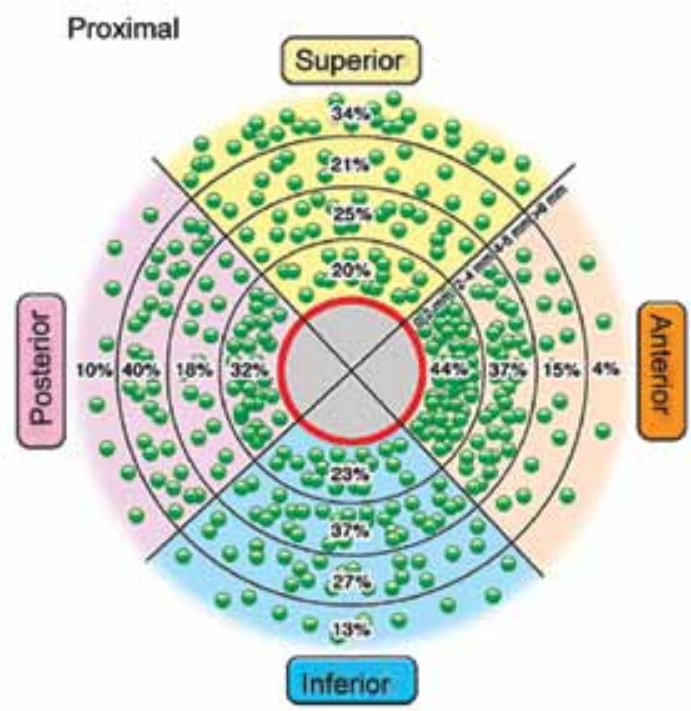

an analgoanesthesia is necessary during the procedure. Heparin is given to achieve an activated clotting time during the procedure of $>250$ seconds. In some patients, the ablation causes renal artery edema/spasm at the treatment sites, which typically disappear within hours after treatment.

External body delivery of focused ultrasound energy to the renal arteries is a novel approach to accomplish RDN. The 'Kona Medical ${ }^{\circledR}$ surround sound system' is a noninvasive treatment that delivers externally focused ultrasound to the renal nerves using Doppler-based ultrasound image guidance to track and correct for renal artery motion during treatment. ${ }^{13}$ This approach has shown promising results in early trials and animal studies. ${ }^{13}$ This technology may offer the advantages of shorter procedure times and less patient discomfort. However, up to now, there is just a little clinical evidence to this new approach available.

\section{CLINICAL STUDIES}

The Symplicity HTN-1 ( $\mathrm{n}=45)$, published in 2009, was the first multicenter proof-of-concept and safety study for patients with resistant arterial hypertension (mean age 58 years), undergoing catheter-based RDN. Patients in the Symplicity HTN-1 study were heavily medicated, taking an average of 4.7 antihypertensive drugs, and were still poorly controlled (office blood pressure 177/101 $\mathrm{mm} \mathrm{Hg}$ ). Four weeks after RDN, a significant reduction of systolic and diastolic office blood pressure by 14 and $10 \mathrm{~mm} \mathrm{Hg}$ has been described, which increased to 27 and $17 \mathrm{~mm} \mathrm{Hg}(p=0.026)$ after 12 months. The published 36 months long-term follow-up indicates a sustained blood pressure lowering effect of 33 and $19 \mathrm{~mm} \mathrm{Hg}$ $(\mathrm{p}<0.01, \mathrm{n}=24)$, making a significant functional regrow or re-innervation of the kidneys unlikely. As secondary

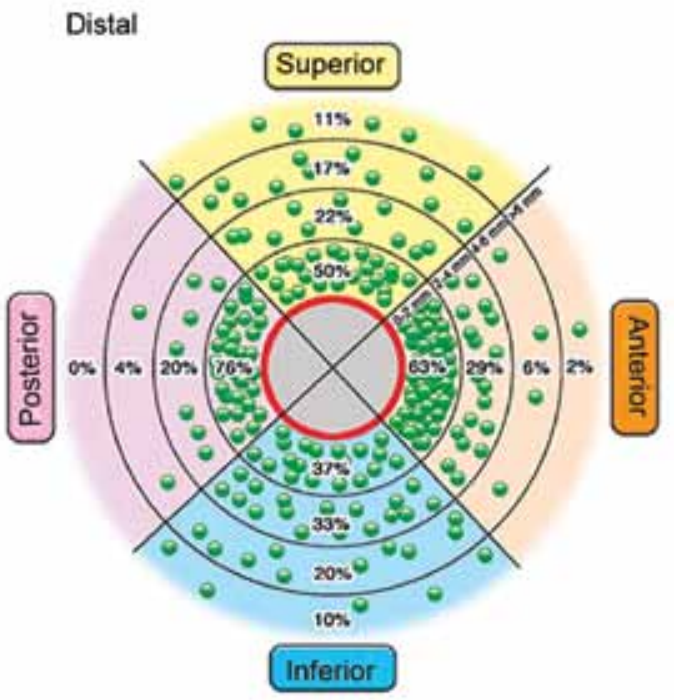

Fig. 1: Sweet spots to target by catheter-based renal denervation ${ }^{10,12}$ 
endpoint, a reduction of renal norepinephrine spillover was significantly reduced by $47 \%(\mathrm{n}=10)$, providing direct evidence for inhibition of sympathetic activation. ${ }^{14}$

Consecutively, the multicenter, prospective, randomized Symplicity HTN-2 trial was conducted. Between June, 2009 and January, 2010, a total of 106 patients with resistant hypertension were randomized 1:1 to a control group (continuation of drug treatment, $\mathrm{n}=54$ ) and a treatment group (RDN plus continued drug treatment, $\mathrm{n}=52) .{ }^{15}$ Six months after RDN, mean blood pressure in the treatment group decreased significantly by $32 / 12 \mathrm{~mm} \mathrm{Hg}$ $(p<0.0001)$, without any changes in the control group. Response to treatment was defined as a reduction in systolic $\mathrm{BP}>10$ $\mathrm{mm} \mathrm{Hg}$ after 6 months and was found in $84 \%$ patients. Reductions in ambulatory blood pressure monitoring over 24 hours in Symplicity HTN-2 were lower as compared to changes in office-based $\mathrm{BP}$, showing a reduction of $11 / 7 \mathrm{~mm} \mathrm{Hg}$ in the intervention group $(\mathrm{p}=0.007, \mathrm{n}=20)$, in contrast to no changes in the control group. A larger prospective multicenter study specifically examined the $\mathrm{BP}$ response to RDN as measured by ambulatory BP monitoring. ${ }^{16}$ In 346 patients who underwent RDN following the Symplicity HTN-2 inclusion criteria, there was also a significant reduction in 24 hours systolic BP by $12 \mathrm{~mm} \mathrm{Hg}$ and diastolic BP by $7 \mathrm{~mm} \mathrm{Hg}$ at 12 months follow-up.

A number of observational studies as well as national and international registries confirmed the results of the first-in-man trials (Graph 1). ${ }^{17,18}$ However, the randomized, blinded, sham-controlled Symplicity HTN-3 trial failed to demonstrate superiority of RDN as compared to a sham procedure in reducing BP after 6 months. ${ }^{19}$ At 6 months follow-up, the average decrease in office and ambulatory systolic $\mathrm{BP}$ in the RDN group was 14 and $7 \mathrm{~mm} \mathrm{Hg}$, as compared to a fall of 12 and $5 \mathrm{~mm} \mathrm{Hg}$ in the control group, respectively. Neither office nor ambulatory differences in BP met the prespecified criteria for statistically significant superiority. Several possible explanations, such as inadequate patient selection, low operator experience and inadequate technical performance of the procedure have been discussed extensively. ${ }^{20,21}$ In line, Kandzari et al showed a subgroup analysis of Symplicity HTN-3 that higher number of ablations and quadrantic ablation in all four quadrants of the arterial wall cross-sections were associated with significant greater ambulatory BP reduction compared to the sham control group (Graph 2). ${ }^{22}$

The recently published randomized RSD-LEIPZIG included 71 patients with resistant hypertension, yet only mildly elevated BP and compared RDN to sham treatment. ${ }^{23}$ In the intention to treat analysis, no significant difference between the groups with respect to 24 hours systolic BP at 6 months (primary endpoint) was observed. However, when analyzed per-protocol, which is likely a better indicator of biological effectiveness of the procedure, RDN was superior to sham. ${ }^{23}$ These results again underline the important role of procedural accuracy and performance.

The prospective, randomized, controlled, multicenter study (DENERHTN) investigated the effect of single electrode Symplicity catheter-based RDN on BP in 121 patients with uncontrolled hypertension. ${ }^{24}$ All eligible patients received a standardized triple antihypertensive treatment (indapamide $1.5 \mathrm{mg}$, ramipril $10 \mathrm{mg}$ or if not tolerated, irbesartan $300 \mathrm{mg}$, and amlodipine $10 \mathrm{mg}$ ) during a 4 weeks run in period. ${ }^{24}$ The remaining 106 patients with resistant hypertension, confirmed by daytime ambulatory BP, were randomly assigned to received RDN or control respectively.

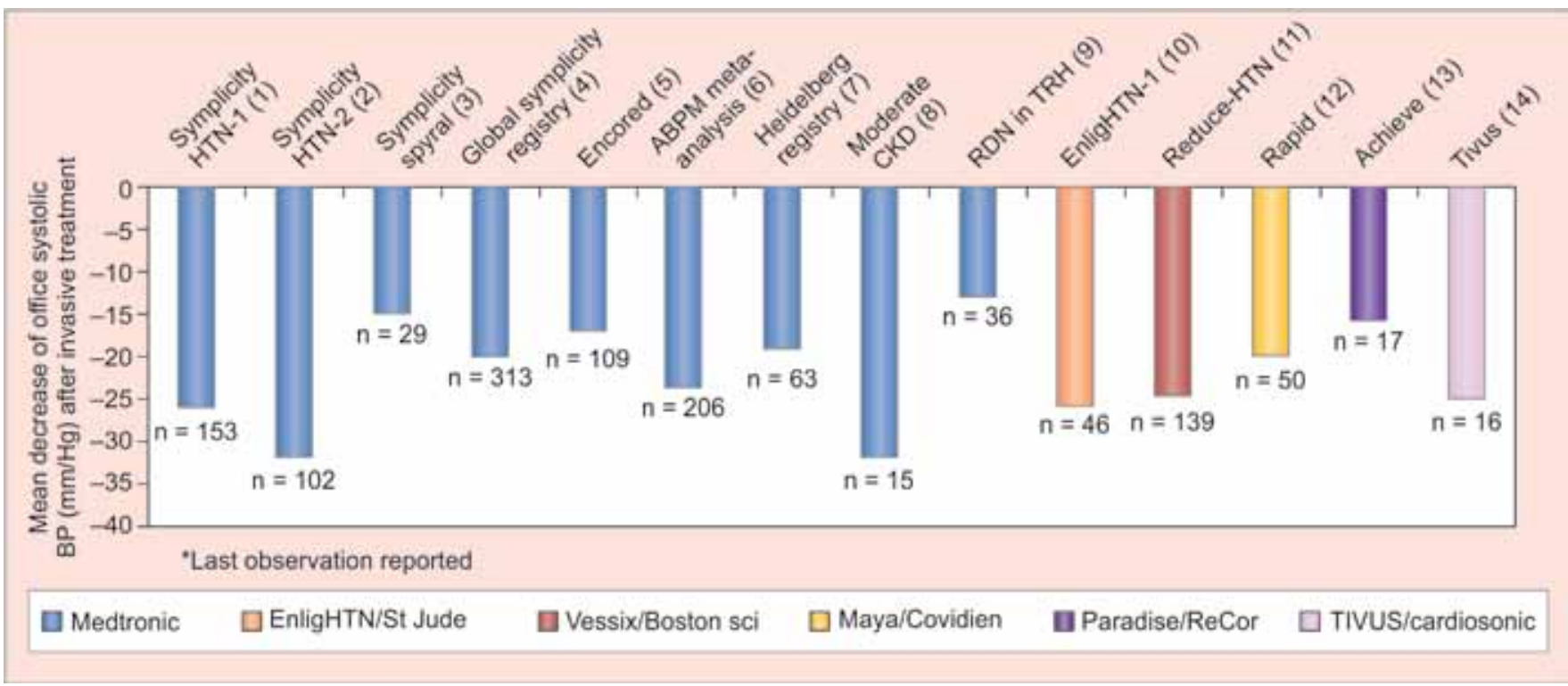

Graph 1: Blood pressure lowering evidence until $2014^{17}$ 


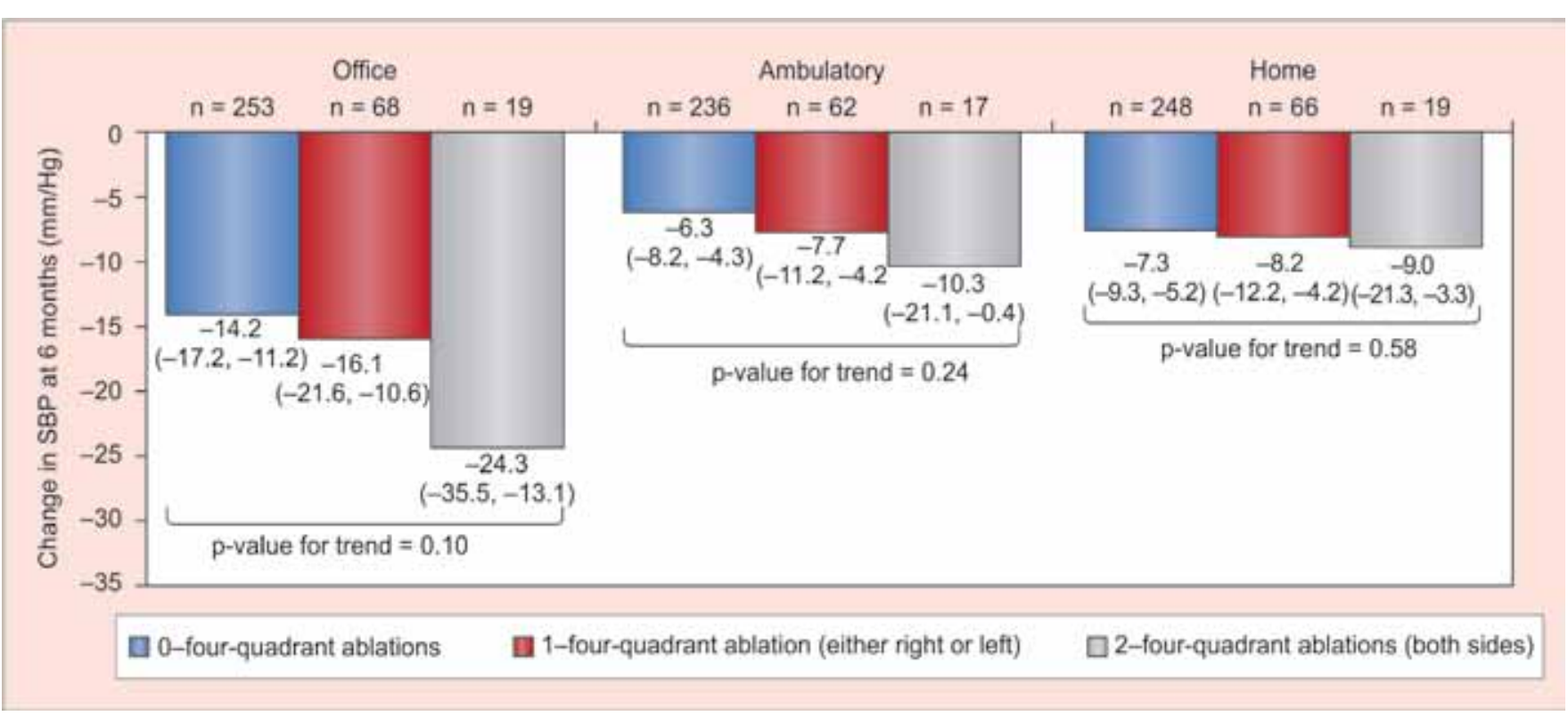

Graph 2: Systolic blood pressure change at symplicity HTN-3 study at 6 months according to ablation pattern ${ }^{22}$

After randomization, patients in both groups received stepped-care antihypertensive drug treatment including spironolactone $25 \mathrm{mg}$, bisoprolol $10 \mathrm{mg}$, prazosin $5 \mathrm{mg}$, and rilmenidine $1 \mathrm{mg}$ daily from months 2 to 5 , if home $\mathrm{BP}$ was $\geq 135 / 85 \mathrm{~mm} \mathrm{Hg}$. The primary efficacy endpoint was met, with a reduction of mean ambulatory daytime systolic BP by $16 \mathrm{~mm} \mathrm{Hg}$ following RDN, as compared to a decreased BP by $10 \mathrm{~mm} \mathrm{Hg}$ in the control group after 6 months. $^{24}$

Finally, the prospective, randomized, open-label multicenter PRAGUE-15 trial investigated the efficacy and safety of catheter-based RDN vs intensified pharmacological treatment, including spironolactone in patients with mild to moderate resistant hypertension (office systolic BP at baseline $>140 \mathrm{~mm} \mathrm{Hg}$ and 24 hours BP $>130$ $\mathrm{mm} \mathrm{Hg}){ }^{25}$ One-hundred six patients were randomized to RDN ( $n=52)$ or intensified pharmacological treatment $(\mathrm{n}=54)$. Both groups significantly reduced office $(-14 \mathrm{~mm} \mathrm{Hg}$ RDN group, $-12 \mathrm{~mm} \mathrm{Hg}$ control) and ambulatory $(-9 \mathrm{~mm} \mathrm{Hg}$ RDN group, $-8 \mathrm{~mm} \mathrm{Hg}$ control) BP as compared to baseline, but there was no significant difference between RDN and intensified pharmacological therapy. However, the average number of antihypertensive drugs used after 6 months was significantly higher in the pharmacological group and a significant more pronounced decrease of creatinine clearance in the pharmacological group was documented.

\section{FUTURE PERSPECTIVE}

Catheter-based RDN has been investigated primarily as a last option in patients with resistant hypertension (defined as systolic BP $\geq 160 \mathrm{~mm} \mathrm{Hg}, \geq 150 \mathrm{~mm} \mathrm{Hg}$ in diabetes mellitus while on a regimen of $\geq 3$ antihypertensive drugs of different classes, including a diuretic, at maximal or highest tolerated dose). ${ }^{26}$ These patients are characterized by a high prevalence of target organ damage, including renal fibrosis and vascular stiffness, which are difficult to reverse whatever methods are used; and thereby not necessarily likely to exhibit the greatest response to RDN therapy. ${ }^{27}$ To improve the efficacy of RDN, the procedure needs to be targeted upon a population with high probability of BP response. This is complicated by: (i) the complex pathophysiology of hypertension, (ii) the lack of clinically applicable, reliable, easy and reproducible measures of 'increased sympathetic activity' that could be used to guide treatment decisions, and (iii) the absence of preprocedural useful predictors of the long-term BP response following RDN. Although the importance of renal nerve signaling in hypertension has been shown by a number of studies and clinical registries, there are many factors besides sympathetic nervous system activation that can drive increases in BP.

However, there is clear evidence indicating that younger patients tend to have greater sympathetic nervous system activation than older patients with hypertension (Graph 3). ${ }^{28}$ Secondly, the arterial wall in younger patients might be more responsive to RDN-induced changes in sympathetic tone, since vascular remodeling might be still in a reversible state. Isolated systolic hypertension (ISH), defined as 'office systolic BP $\geq 140$ $\mathrm{mm} \mathrm{Hg}$ and diastolic $\mathrm{BP}<90 \mathrm{~mm} \mathrm{Hg}$ ', is the predominant hypertensive subtype in elderly patients. ${ }^{29}$ Isolated systolic hypertension is characterized by an increased aortic stiffness, increased pressure wave reflections and low pulse pressure amplification..$^{29}$ Data indicate that ISH is associated with limited response to RDN, as it could 


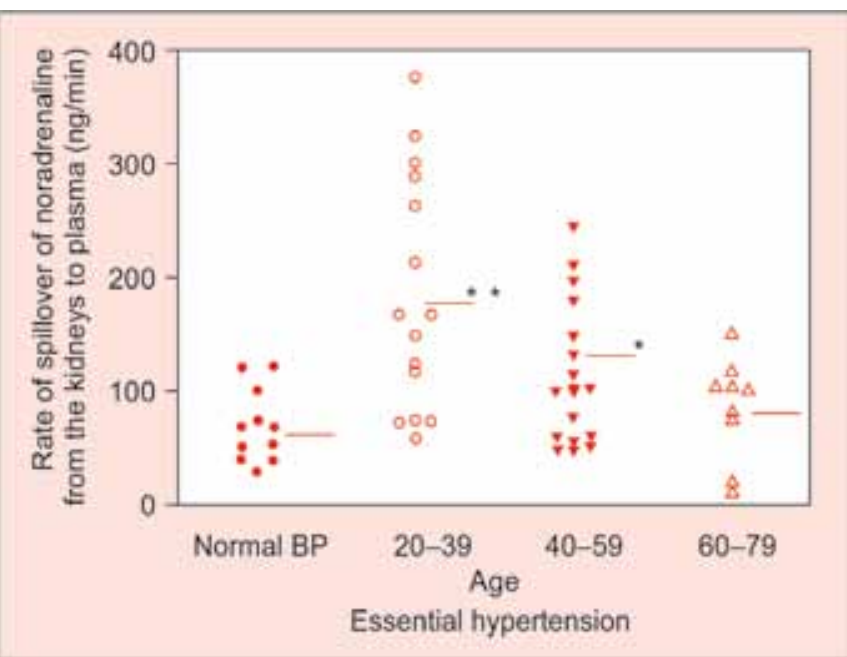

Graph 3: Sympathetic nerve activity according to age in patients with hypertension ${ }^{28}$

be expected from drug trials. ${ }^{30,31}$ Accordingly, increased central pulse pressure indicates aortic stiffness and is related to worse BP response after RDN. ${ }^{32}$ Clearly, there is a need for more research on this topic and an urgent need to delineate predictors of $\mathrm{BP}$ response following RDN.

Accordingly, the multicenter, prospective, single blind, randomized, placebocontrolled REDUCE-HTN: REINFORCE study (NCT02392351) is enrolling patients in the US, who are not on medication, and will focus primarily on the mean reduction in average 24 hours ambulatory systolic BP at 8 weeks post-randomization. Furthermore, the multicenter, prospective, single blind, randomized, sham-controlled SPYRAL HTN-OFF MED (NCT02439749) and SPYRAL HTN-ON MED (NCT02439775) studies will start enrolling approximately 100 patients with moderate to severe hypertension. These studies will be conducted at approximately 20 centers in Europe, the US, Japan and Australia. The SPYRAL HTNOFF MED study is designed to specifically investigate the effect of RDN on BP in patients not receiving any antihypertensive medication. Separately, the SPYRAL HTN-ON MED study will evaluate the effect of RDN on BP in patients with uncontrolled BP despite the intake of three commonly used antihypertensive agents. Adherence will be closely monitored to ensure consistency between both arms of the on- and off-medication studies.

\section{CONCLUSION}

In patients with confirmed treatment-resistant hypertension, catheter-based RDN offers a safe and effective treatment approach to reduce sympathetic activity and BP over at least 36 months in selected patients. However, further randomized clinical trials are needed to systematically assess the effect of RDN in patients with uncontrolled hypertension in order to identify reliable predictors of response. Is there a hope of resurgence of RDN after the Symplicity HTN-3 trial failed to meet its efficacy endpoint? Our unequivocal answer is Yes.

\section{REFERENCES}

1. Kearney PM, Whelton M, Reynolds K, Muntner P, Whelton PK, He J. Global burden of hypertension: analysis of worldwide data. Lancet 2005;365(9455):217-223.

2. Calhoun DA, Jones D, Textor S, Goff DC, Murphy TP, Toto RD, White A, Cushman WC, White W, Sica D, et al. Resistant hypertension: diagnosis, evaluation and treatment: a scientific statement from the American Heart Association Professional Education Committee of the Council for High Blood Pressure Research. Circulation 2008;117(25):e510-526.

3. Judd E, Calhoun DA. Apparent and true resistant hypertension: definition, prevalence and outcomes. J Hum Hypertens 2014;28(8):463-468.

4. Mancia G, De Backer G, Dominiczak A, Cifkova R, Fagard R, Germano G, Grassi G, Heagerty AM, Kjeldson SE, LaurantS, et al. 2007 Guidelines for the Management of Arterial Hypertension: the task force for the management of arterial hypertension of the European Society of Hypertension (ESH) and of the European Society of Cardiology (ESC). J Hypertens 2007;25(6):1105-1187.

5. Mahfoud F, Himmel F, Ukena C, Schunkert H, Böhm M, WeilJ. Treatment strategies for resistant arterial hypertension. Dtsch Arztebl Int 2011;108(43):725-731.

6. Grassi G. Assessment of sympathetic cardiovascular drive in human hypertension: achievements and perspectives. Hypertension 2009;54(4):690-697.

7. Sobotka PA, Mahfoud F, Schlaich MP, Hoppe UC, Böhm M, Krum H. Sympathorenal axis in chronic disease. Clin Res Cardiol 2011;100(12):1049-1057.

8. Parati G, Esler M. The human sympathetic nervous system: its relevance in hypertension and heart failure. Eur Heart J 2012;33(9):1058-1066.

9. DiBona GF. Physiology in perspective: the Wisdom of the Body. Neural control of the kidney. Am J Physiol Regul Integr Comp Physiol 2005;289(3):R633-641.

10. Sakakura K, Ladich E, Cheng Q, Otsuka F, Yahagi K, Fowler DR, Kolodgie FD, Virmani R, Joner M. Anatomic assessment of sympathetic periarterial renal nerves in man. J Am Coll Cardiol 2014;64(7):635-643.

11. Tzafriri AR, Mahfoud F, Keating JH, Markham PM, Spognardi A, Wong G, Fuimaono K, Böhm M, Edelman ER. Innervation patterns may limit response to endovascular renal denervation. J Am Coll Cardiol 2014;64(11):1079-1087.

12. Mahfoud F, Edelman ER, Böhm M. Catheter-based renal denervation is no simple matter: lessons to be learned from our anatomy? J Am Coll Cardiol 2014;64(7):644-646.

13. Ormiston J, Anderson T, Brinton TJ, Dawood O, Gertner M, Kay P, Neuzil P, Starek Z. TCT-412 Noninvasive renal denervation using externally delivered focused ultrasound: early experience using doppler based imaging tracking and targeting for treatment. J Am Coll Cardiol 2014;64(11 Suppl):B121.

14. Krum H, Schlaich M, Whitbourn R, Sobotka PA, Sadowski J, Bartus K, Kapelak B, Walton A, Sievert H, Thambar S, et al. Catheter-based renal sympathetic denervation for resistant 
hypertension: a multicentre safety and proof-of-principle cohort study. Lancet 2009;373(9671):1275-1281.

15. Symplicity HTN-2 Investigators, Esler MD, Krum H, Sobotka PA, Schlaich MP, Schmieder RE, Böhm M. Renal sympathetic denervation in patients with treatment-resistant hypertension (The Symplicity HTN-2 Trial): a randomised controlled trial. Lancet 2010;376(9756):1903-1909.

16. Mahfoud F, Ukena C, Schmieder RE, Cremers B, Rump LC, Vonend O, Weil J, Schmidt M, Hoppe UC, Zeller T, et al. Ambulatory blood pressure changes after renal sympathetic denervation in patients with resistant hypertension. Circulation 2013;128(2):132-140.

17. Ott C, Schmieder RE. Invasive treatment of resistant hypertension: present and future. Current Hypertension Reports 2014;16(11):488.

18. Böhm M, Mahfoud F, Ukena C, Hoppe UC, Narkiewicz K, Negoita M, Ruilope L, Schlaich MP, Schmieder RE, Whitbourn R, et al. First Report of the Global Symplicity registry on the effect of renal artery denervation in patients with uncontrolled hypertension. Hypertension 2015;65(4):766-774.

19. Bhatt DL, Kandzari DE, O'Neill WW, D'Agostino R, Flack JM, Katzen BT, Leon MB, Liu M, Mauri L, Negoita M, et al. A controlled trial of renal denervation for resistant hypertension. N Engl J Med 2014;370(15):1393-1401.

20. Pathak A, Ewen S, Fajadet J, Honton B, Mahfoud F, Marco J, Schlaich M, Schmieder R, Tsioufis K, Ukena C, et al. From Symplicity HTN-3 to the renal denervation global registry: where do we stand and where should we go? EuroIntervention 2014;10(1):21-23.

21. Mahfoud F, Lüscher TF. Renal denervation: symply trapped by complexity? Eur Heart J 2015;36(4):199-202.

22. Kandzari DE, Bhatt DL, Brar S, Devireddy CM, Esler M, Fahy M, Flack JM, Katzen BT, Lea J, Lee DP, et al. Predictors of blood pressure response in the Symplicity HTN-3 trial. Eur Heart J 2015;36(4):219-227.

23. Desch S, Okon T, Heinemann D, Kulle K, Rohnert K, Sonnabend M, Petzold M, Muller U, Schuler G, Eitel I, et al. Randomized sham-controlled trial of renal sympathetic denervation in mild resistant hypertension. Hypertension 2015;65(6):1202-1208

24. Azizi M, Sapoval M, Gosse P, Monge M, Bobrie G, Delsart P, Midulla M, Mounier-Vehier C, Courand PY, Lantelme P, et al. Optimum and stepped care standardised antihypertensive treatment with or without renal denervation for resistant hypertension (DENERHTN): a multicentre, open-label, randomised controlled trial. The Lancet 2015;385(9981): 1957-1965.

25. Rosa J, Widimsky P, Tousek P, Petrak O, Curila K, Waldauf $\mathrm{P}_{\text {, }}$ Bednář F, Zelinka T, Holaj R, Štrauch B, et al. Randomized comparison of renal denervation versus intensified pharmacotherapy including spironolactone in true-resistant hypertension: six-month results from the prague-15 study. Hypertension 2015;65(2):407-413.

26. Mahfoud F, Lüscher TF, Andersson B, Baumgartner I, Cifkova R, Dimario C, Doevendans P, Fagard R, Fajadet J, Komajda M, et al. Expert consensus document from the European Society of Cardiology on catheter-based renal denervation. Eur Heart J 2013;34(28):2149-2157.

27. Mahfoud F, Bohm M, Azizi M, Pathak A, Durand Zaleski I, Ewen S, Tsioufis K, Andersson B, Blankestijn PJ, Burnier M, et al. Proceedings from the European clinical consensus conference for renal denervation: considerations on future clinical trial design. European Heart J 2015;ehv192.

28. Esler M, Jennings G, Korner P, Willett I, Dudley F, Hasking G, Anderson W, Lambert G. Assessment of human sympathetic nervous system activity from measurements of norepinephrine turnover. Hypertension 1988;11(1):3-20.

29. Franklin SS, Jacobs MJ, Wong ND, L'Italien GJ, Lapuerta P. Predominance of isolated systolic hypertension among middle-aged and elderly US hypertensives: analysis based on National Health and Nutrition Examination Survey (NHANES) III. Hypertension 2001;37(3):869-874.

30. Ewen S, Ukena C, Linz D, Kindermann I, Cremers B, Laufs U, Wagenpfeil S, Schmieder RE, Bohm M, mahfoud F. Reduced effect of percutaneous renal denervation on blood pressure in patients with isolated systolic hypertension. Hypertension 2015;65(1):193-199.

31. Mackenzie IS, McEniery CM, Dhakam Z, Brown MJ, Cockcroft JR, Wilkinson IB. Comparison of the effects of antihypertensive agents on central blood pressure and arterial stiffness in isolated systolic hypertension. Hypertension 2009;54(2):409-413.

32. Ott C, Schmid A, Toennes SW, Ditting T, Veelken R, Uder M, Schmieder RE. Central pulse pressure predicts BP reduction after renal denervation in patients with treatment-resistant hypertension. Euro Intervention 2015;11(1):110-116. 